\title{
Registros rupestres do Parque Nacional Serra da Capivara-Piauí: breves reflexões sobre a pesquisa antropológica na educação e suas perspectivas interdisciplinares
}

\author{
Rupestrian records of the National Park Serra da Capivara-Piauí: brief \\ reflections on anthropological research in education and its interdisciplinary \\ perspectives
}

\begin{abstract}
Antoniel dos Santos Gomes Filho ${ }^{a}$
Michel Justamand ${ }^{\mathrm{b}}$

a Mestre em Educação pela Universidade Federal do Ceará (UFC). Docente da Faculdade Vale do Salgado (FVS).

E-mail: antoniel.historiacomparada@gmail.com;antonielsantos@fvs.edu.br

b Doutor em Antropologia e Pós-Doutor em História (ambos pela PUC/SP) e Pós-Doutor em Arqueologia (UNICAMP). Docente da Universidade Federal do Amazonas - UFAM, lotado na unidade acadêmica do Alto Solimões, na cidade de Benjamin Constant/AM, no Instituto de Natureza e Cultura - INC. E-mail: micheljustamand@yahoo.com.br
\end{abstract}

Recebido em: 22/02/2018 I Aceito em: 11/06/2018

\section{RESUMO}

A investigação apresentada em tela entrelaça a antropologia da educação e os registros rupestres do Parque Nacional Serra da Capivara (PNSC) com sede no município de São Raimundo no Estado do Piauí, Brasil. O estudo teve como proposta maior, realizar algumas breves reflexões sobre as possíveis conexões que os registros rupestres localizados no PNSC e suas possibilidades de desencadear investigações no campo da antropologia da educação. Os itinerários metodológicos de base qualitativa são múltiplos, indo desde os contextos formativos no campo da antropologia, onde o primeiro autor se considera um "antropólogo da educaçãoaprendiz", até o desenvolvimento de pesquisas antropológicas e arqueológicas no PNSC no início de 2018, sobre as cenas rupestres de sexo e práticas sexuais de nossos ancestrais. Diante desses caminhos, a investigação considera que os estudos em antropologia da educação, em perspectiva interdisciplinar com a história e a arqueologia, podem proporcionar novos olhares sobre a educação e sobre as instituições escolares e seus funcionamentos materiais e simbólicos, já que através da prática etnográfica pode-se compreender 0 cotidiano destes espaços, 
Registros rupestres do Parque Nacional Serra da Capivara-Piauí: breves reflexões sobre a pesquisa antropológica na educação e suas perspectivas interdisciplinares

conhecendo assim a formação de uma cultura própria do lócus estudado, bem como suas relações com a sociedade.

Palavras-chave: Antropologia da Educação. Educação Brasileira. Parque Nacional Serra da Capivara. Registros Rupestres. Etnografia.

\section{ABSTRACT}

The research presented on the screen interweaves the anthropology of education and the rock records of Serra da Capivara National Park (PNSC), based in the municipality of São Raimundo in the State of Piauí, Brazil. The purpose of the study was to make some brief reflections on the possible connections that the rupestrian records located in the PNSC and its possibilities of triggering investigations in the field of the anthropology of education. The methodological itineraries with a qualitative basis are multiple, ranging from the formative contexts in the field of anthropology, where the first author considers himself an "anthropologist of education-apprentice", until the development of anthropological and archaeological research in the PNSC in early 2018, on the rupestrian scenes of sex and the sexual practices of our ancestors. Faced with these paths, the research considers that studies in anthropology of education, in an interdisciplinary perspective with history and archeology, can provide new insights on education and on school institutions and their material and symbolic functions, since through ethnographic practice one can understand the daily life of these spaces, thus knowing the formation of a culture of the locus studied, as well as their relations with society.

KEYWORD: Anthropology of Education. Brazilian Education. National Park Serra da Capivara. Rupestrian Records. Ethnography.

\section{INTRODUÇÃO}

A pesquisa antropológica na educação brasileira vem sendo desenvolvida com maior sistematicidade a partir das últimas duas décadas (BESERRA et al., 2017). Mas, as aproximações entre antropologia e educação datam o final do século XIX, quando já se torna perceptível uma busca pela compreensão das culturas infantis e juvenis e os sistemas de educação informal, estendendo-se e tomando diversos rumos teórico-metodológicos no século seguinte, como aponta Neusa Gusmão (1997).

Conforme escreve a antropóloga e professora, Bernadete Beserra et al. (2017) da Universidade Federal do Ceará (UFC), um dos grandes desafios da pesquisa antropológica na educação na atualidade está em seu caráter formativo, uma vez que "antropólogos da educação-aprendizes", não são oriundos dos cursos 
de formação específicos em antropologia ou ciências sociais, se deparando com a antropologia e a experiência etnográfica nos cursos de pós-graduação. Em consonância com essa questão, Neusa Gusmão (1997, s/p) em fins da década de 1990, já apontava que nos diálogos entre antropologia e educação, e que, no próprio fazer da antropologia da educação, um dos desafios estava ligado em,

[...] trazer o aluno da pedagogia para uma aproximação no campo teórico da antropologia, que the é inteiramente desconhecido. Por outro lado, o aluno de ciências sociais, campo onde o antropólogo é formado, no caso brasileiro, também desconhece o itinerário da antropologia no campo da educação (GUSMÃO, 1997, s/p).

Considerando que é a partir dos desafios postos, que as possibilidades de um fazer antropológico da educação ampliam-se, em especial, como aponta Bernadete Beserra et al. (2017) através da oferta de disciplinas específicas de Antropologia, e de disciplinas que promovam a interdisciplinaridade entre a já citada antropologia, mas também entre a história, a arqueologia (JUSTAMAND, 2005) e a sociologia nos cursos de pós-graduação (mestrado e doutorado).

É neste caminho interdisciplinar que nos situamos, um de nós, Gomes Filho, como "antropólogos da educação-aprendiz", já que não somos oriundos de uma formação específica no referido campo, nos deparamos com a antropologia da educação no período em que estivemos no Programa de Pós-graduação em Educação da UFC (mestrado), em dois momentos distintos. O primeiro, no Seminário de Educação Brasileira, ministrado por Juraci Cavalcante ${ }^{1}$, onde organizou-se a III Expedição Serra da Capivara, que resultou no estudo intitulado: Uma aproximação entre arqueologia e educação: relato de uma expedição ao Parque Nacional Serra da Capivara (GOMES FILHO; MORAIS, 2017c); e o segundo, na disciplina de Antropologia da Performance ${ }^{2}$, ministrado pelos Professores Alexandre Fleming e Eloi Magalhães, que resultou na publicação do artigo intitulado: Performances de travestis nas terras consagradas a São Francisco das Chagas:

\footnotetext{
1 Sobre o Seminário de Educação Brasileira do ano de 2015-2016 ver: CAVALCANTE, Maria Juraci Maia. À guisa de introdução: a última aula do seminário de educação brasileira. In: GOMES FILHO, Antoniel dos Santos.; MEDEIROS, Jarles Lopes.; CAVALCANTE, Maria Juraci Maia. (Orgs.). Educação Brasileira: ensaios iniciáticos em torno da crise da escola e dos desafios do mundo contemporâneo. Fortaleza: Edições UFC, 2017.

2 Disciplina ofertada no Programa de Pós-graduação em Sociologia da UFC.

Ciência e Sustentabilidade - CeS / Juazeiro do Norte, v. 4, n. 1, p. 22-38, jan/jun - 2018
} 
Registros rupestres do Parque Nacional Serra da Capivara-Piauí: breves reflexões sobre a pesquisa antropológica na educação e suas perspectivas interdisciplinares

uma experiência etnográfica no município de Canindé-Ceará, Brasil (GOMES FILHO; MAGALHÃES, 2017b), sendo este, um estudo com base no método etnográfico, tão salutar para os estudos antropológicos da educação, já que "o conhecimento antropológico propõe, de certo modo, um discurso mais concreto, mais calcado no reconhecimento às sociabilidades cotidianas" (BESERRA et al. 2017, p. 17).

É a partir da interdisciplinaridade e de parcerias com outros pesquisadores do país, tendo como ponto de partida a III Expedição Serra da Capivara, que surgiu o interesse nas pesquisas antropológicas e arqueológicas sobre os registros rupestres do Parque Nacional Serra da Capivara (PNSC), localizado no Estado do Piauí. Como aponta Sádia Castro (2011, p. 31, grifo nosso), os registros rupestres são "uma crônica instigante da vida de nossos ancestrais, mostrando detalhadamente como eram as primeiras sociedades que por ali passaram, suas festas, rituais religiosos, caça, pesca e uma incidência impressionante de cenas de sexo". É sobre essa incidência de cenas de sexo e de práticas sexuais, que junto com Michel Justamand, da Universidade Federal do Amazonas (UFAM) e Leandro Colling da Universidade Federal da Bahia (UFBA), entre os dias 29 de Janeiro e 05 de Fevereiro do corrente ano, realizamos nova expedição de pesquisa, onde o objetivo era o registro fotográfico de registros rupestres de cenas de sexo e práticas sexuais $^{3}$, tema que já havíamos estudado para a elaboração da dissertação de mestrado, que versou sobre a educação e as questões de gênero e sexualidade (GOMES FILHO, 2017a).

É através desses itinerários formativos que surge o despertar para os estudos no campo da antropologia da educação em perspectiva interdisciplinar, que propomos neste artigo realizar algumas "breves" reflexões sobre as possíveis conexões que os registros rupestres localizados no PNSC podem desencadear investigações no campo da antropologia da educação. Destacamos que as aspas que acompanham o termo breve, seguem os rumos dos itinerários de "antropólogo da educação-aprendiz" que ainda são breves, em seu sentido literal, mas, que aos poucos se ampliam a cada ida a campo, em conversas com informantes, nas novas observações dos registros rupestres e nas orientações com os professores e

3 Além dos referidos professores compuseram a equipe de pesquisa a geografa e arqueóloga Vanessa Belarmino e Mário, guia registrado junto ao Parque Nacional Serra da Capivara. 
professoras parceiros na construção do (re)conhecimento sobre a educação brasileira.

\title{
2 O PARQUE NACIONAL SERRA DA CAPIVARA: O COTIDIANO DOS POVOS DAS TERRAS BRASILIS ANTES DE 1500 E AS PESQUISAS ANTROPOLOGICAS NA EDUCAÇÃO
}

\begin{abstract}
Esta carta é da região do grande Brasil e do lado ocidental alcança as Antilhas do Rei de Castela. Quanto à sua gente, é de cor um tanto escuro. Selvagem e crudelíssima, alimenta-se de carne humana. Este mesmo povo emprega, de modo notável, o arco e as setas. (BIBLIOTECA NACIONAL DIGITAL, 2015, s/p).
\end{abstract}

A descrição dos povos das Terras Brasilis, contida no mapa ${ }^{4}$ de mesmo nome, apresenta os povos do novo mundo como selvagens e cruéis e, como aponta Jörn Seemann (2007), os mapas produzidos na "era do descobrimento" estão carregados de contextos históricos e elementos não-verbais, que apontam os olhares europeus sobre esse povo que domina notavelmente o arco e a flecha.

Os escritos contidos no Terras Brasilis nos dão indícios de que os povos das terras descobertas se afastam da que é considerado humano no século XVI, já que: "Seus gostos repugnam. Sua violência revolta. Seu abandono a Deus horroriza." (VIGARELLO, 2013, p. 468). Os relatos do "novo mundo" percorreram o "mundo antigo", sendo este encontro foco de muitos escritos, que vão dos relatos de viagem, até os livros considerados clássicos para a educação, afinal, o Emílio de Rousseau precisa ser educado para um novo mundo. Um mundo, onde selvagens já se fazem presente. É a partir desse encontro que surge a reflexão antropológica contemporânea, como diz François Laplatine (2007).

Esta sucinta consideração sobre o encontro entre europeus e os povos das Américas, nos mostra que para "entender o que somos como povo e nação, e aquilo que chamamos, com tanta simplicidade de 'educação brasileira' [é preciso ter] em vista esta articulação temporal e política com os últimos cinco séculos de expansão

\footnotetext{
${ }^{4}$ O mapa Terra Brasilis foi produzido no ano de 1519 pelo cartógrafo da corte portuguesa Lopo Homem, e pelos cartógrafos Pedro e Jorge Reinel, sendo oferecido ao Rei Francisco I como presente de D. João III de Portugal (SEEMANN, 2007). O mapa está disponível para visualização digital via Biblioteca Nacional Digital (Brasil). O endereço eletrônico está contido nas referências do presente estudo.
}

Ciência e Sustentabilidade - CeS / Juazeiro do Norte, v. 4, n. 1, p. 22-38, jan/jun - 2018 
Registros rupestres do Parque Nacional Serra da Capivara-Piauí: breves reflexões sobre a pesquisa antropológica na educação e suas perspectivas interdisciplinares

europeia [...]" (CAVALCANTE, 2017, p. 25). Assim, quando propomos neste artigo refletir sobre os tempos e os povos antes de 1500 (JUSTAMAND, 2012a), e suas repercussões para a Educação Brasileira e para a produção de uma antropologia da educação, estamos conscientes da geopolítica do conhecimento, que contemporaneamente vem deslocando e desconstruindo essa centralidade da Europa de ícone do poder colonial e pós-colonial, como aponta Boaventura de Sousa Santos (2016).

É neste contexto de pensar sobre os povos que viveram nas Terras Brasilis antes de 1500, a partir de epistemologias produzidas no Brasil e/ou ao sul global, que o PNSC se mostra como um lócus de reflexão sobre a pesquisa antropológica na educação cultural brasileira (JUSTAMAND, 2006a).

O PNSC, que conta com uma com área de 100.000 hectares, no ano de 1991 foi inscrito pela Organização das Nações Unidas para a Educação, a Ciência e a Cultura (UNESCO) na lista do Patrimônio Cultural da Humanidade, sendo de responsabilidade da Fundação Museu do Homem Americano (FUMDHAM) a preservação do parque, que ganhou esse status em 5 de junho de 1979, a partir do Decreto ํㅡ 83.548. A proteção ao Parque foi ampliada pelo Decreto de nำ 99.143 de 12 de março de 1990, com a criação de Áreas de Preservação Permanentes adjacentes com total de 35.000 hectares. Localizado no semiárido nordestino, fronteira entre duas formações geológicas, com serras, vales e planícies, o parque abriga fauna e flora específicas da Caatinga. A Portaria Ministério do Meio Ambiente no 76, de 11 de março de 2005, criou um Mosaico de Unidades de Conservação abrangendo os Parques Nacionais Serra da Capivara e Serra das Confusões e o Corredor Ecológico conectando os dois parques. A área total do Corredor Ecológico é de 414 mil hectares, abrangendo os municípios de São Raimundo Nonato, Coronel José Dias, Canto do Buriti, São João do Piauí, Tamboril do Piauí, Brejo do Piauí, São Braz, Anísio de Abreu, Jurema, Caracol e Guaribas. No Parque encontra-se a maior concentração de sítios arqueológicos atualmente conhecidos nas Américas, com mais de mil sítios cadastrados. Nos abrigos, além das manifestações gráficas, encontram-se vários vestígios da presença do homem pré-histórico, com datações mais antigas conhecidas no continente americano. A região abriga 173 sítios 
arqueológicos abertos à visitação. (ICMBIO, 2016; FUMDHAM, 2018; UNESCO, 2018; JUSTAMAND et al., 2017; PESSIS; GUIDON, 2000; GUIDON, 2003).

Diante de tantos patrimônios naturais, materiais e culturais que o PNSC concentra, vamos prestigiar nesse estudo as manifestações gráficas, ou seja, os registros rupestres, deixado pelos povos que habitaram a região entre 18 mil anos antes das chegadas dos povos europeus, conforme apontam as pesquisas arqueológicas (PESSIS; GUIDON, 2000).

Os registros rupestres, como informa Gabriela Martin (1997), constituem-se uma fonte de informação científica para os estudos antropológicos, uma vez que através do estudo sistemático dos registros gráficos em tradição, subtradição e estilo, os pesquisadores ultrapassam os limites dos estudos descritivos (JUSTAMAND, 2005). Como explicam Anne-Marie Pessis e Niède Guidon (2000, p. 21) as "diferenças sobre o plano da apresentação gráfica refletem diferenças culturais, pois os padrões sociais de apresentação são determinantes dos primeiros. Os registros rupestres funcionam como verdadeiros sistemas de comunicação social [...]". Também compreendendo os registros rupestres como sistemas comunicativos, o antropólogo Michel Justamnd (2011; 2012b; 2016; 2017) nos informa que as pinturas plasmadas nas rochas formam uma linguagem sobre as formas de sociabilidade dos povos que ali estiveram. Em suas palavras:

\begin{abstract}
A contribuição das pinturas rupestres como forma de linguagens e testemunhos, inclusive para evidenciar os corpos, foi de grande valia para os grupos que em outros tempos transitaram pela região e pelo país. Contribuíram para o desenvolvimento da História grupal e para as suas comunicações e seus conhecimentos territoriais. Por serem testemunhos do cotidiano, registraram os fatos que ocorreram em tempos imemoriais, em território tupiniquim, além de nos apresentarem suas identidades sociais. Há muitos corpos antropomorfizados e/ou humanos com indumentárias, vestimentas e atributos como cocares (JUSTAMAND, 2011, p. 228-229).
\end{abstract}

Os testemunhos do cotidiano estão registrados nas rochas dos sítios do PNSC, nos apresentam três grandes cenas e/ou temáticas: (01) a caça e a coleta, (02) os ritos e hierarquias e (03) as práticas sexuais (MARTIN, 1997; PESSIS; GUIDON, 2000). Essas temáticas podem ser observadas nas fotos dos registros rupestres apresentados a seguir:

Ciência e Sustentabilidade - CeS / Juazeiro do Norte, v. 4, n. 1, p. 22-38, jan/jun - 2018 
Registros rupestres do Parque Nacional Serra da Capivara-Piauí: breves reflexões sobre a pesquisa antropológica na educação e suas perspectivas interdisciplinares

Figura 1: Cena de caça. Local: Toca do Estevo III.

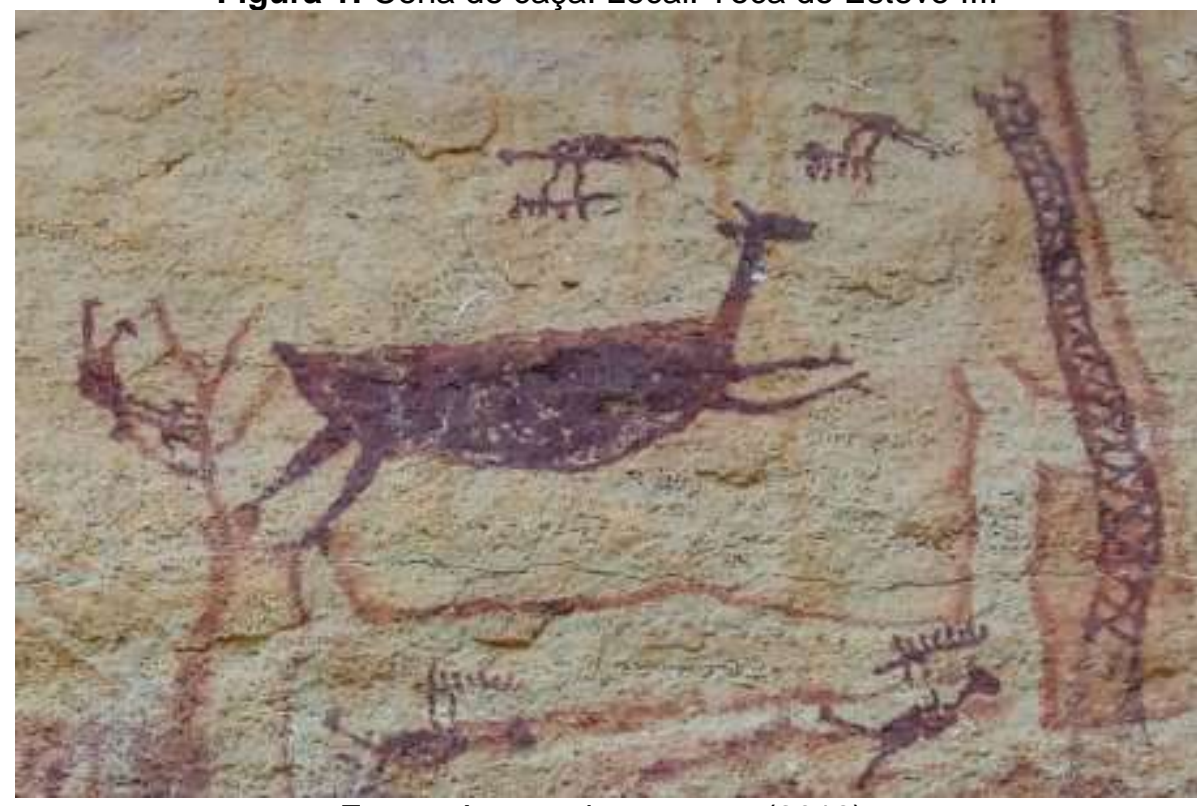

Fonte: Acervo dos autores (2018).

Nas diversas cenas de caça pode-se observar que nossos ancestrais já utilizavam instrumentos tais como redes, tacapes, propulsores e azagais, não são encontrados nos registros o uso de arcos e flechas (PESSIS; GUIDON, 2000).

Figura 2: Um possível ritual ou dança. Antropomorfos com adornos na cabeça. Local: Toca de cima do fundo do BPF.

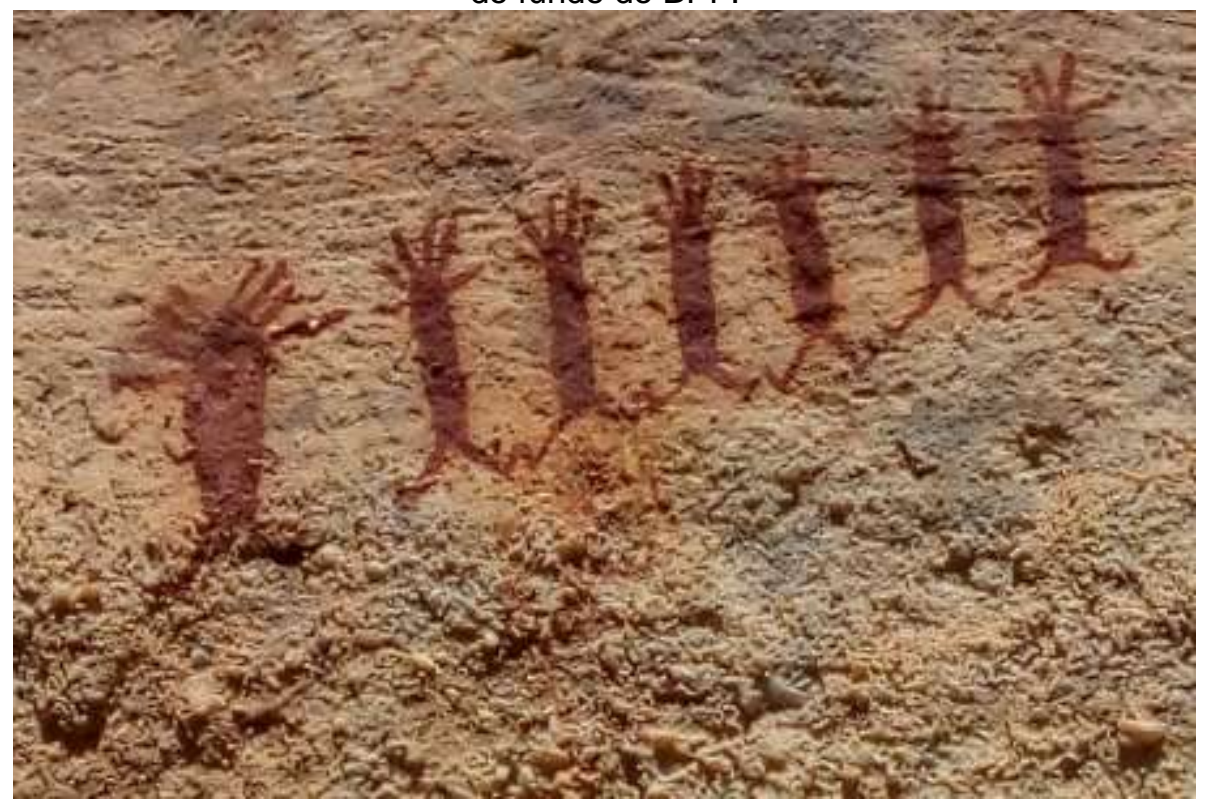

Fonte: Acervo dos autores (2018). 
Como se observa, nos registros as representações dos antropomorfos são bem geometrizadas, porém ainda assim conseguem transparecer a ideia de movimento gestual (MARTINS, 1997). Outra imagem, emblemática que sugere um ritual é chamada de As orantes, que segundo Martin e Guidon (2010) não realizam nenhuma atividade dentro dos padrões encontrados nos demais registros, e sua posição lembra pessoas contemporâneas em posição e ornamentação para rituais de oração.

Figura 3: As orantes. Local: Toca do Estevo III.

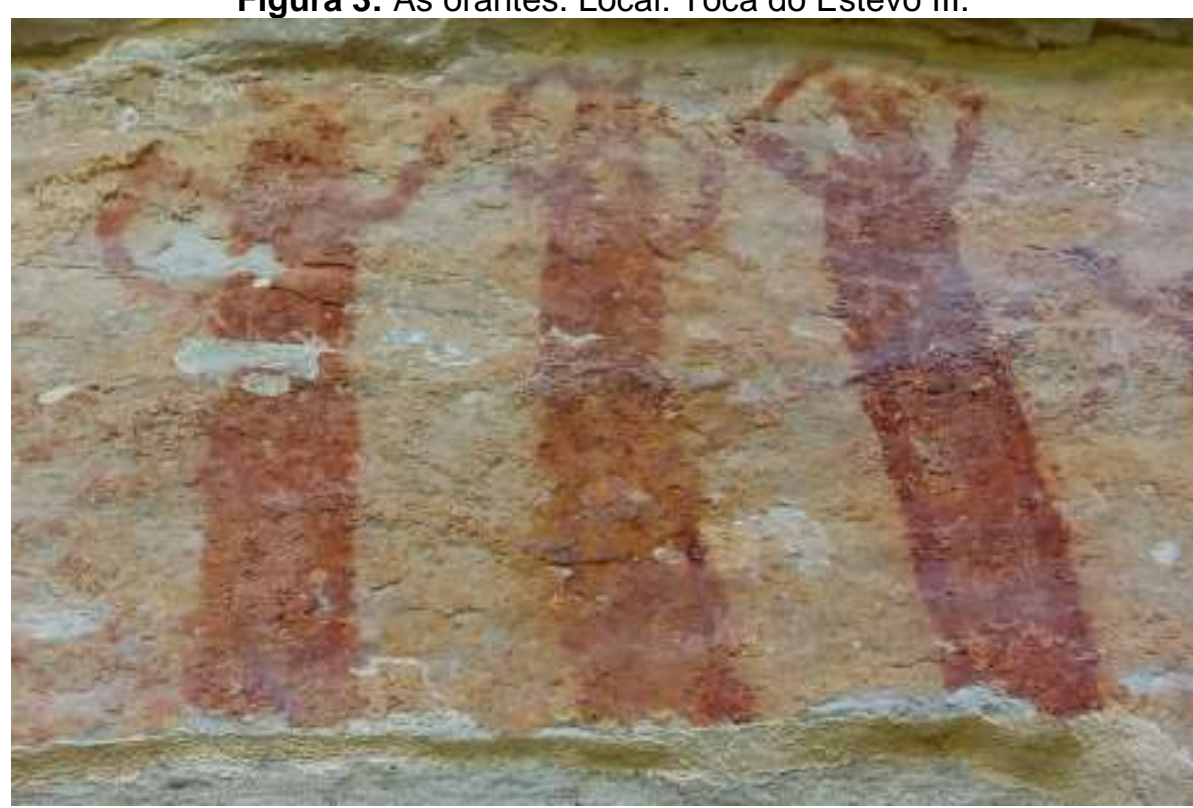

Fonte: Acervo dos autores (2018).

As cenas de práticas sexuais e exposição das genitálias são constantes nos diversos sítios arqueológicos do PNSC. Conforme as hipóteses levantadas por Justamand e Funari (2016), no estudo intitulado: Representações das genitálias femininas e masculinas nas pinturas rupestres no Parque Nacional Serra da Capivara, PI, Brasil, os pintores rupestres tinham,

[...] uma seleção intencional dos grupos, com seus autores e pintores, dos paredões mais adequados para a sua cultura, para pintarem suas cenas diversas, e, em especial, as genitálias. [...] Supomos que pintavam as genitálias onde julgavam ser mais importantes, necessários e significativos para si e para os que participavam daquelas sociedades. [...] Dessa forma, as cenas com falos e vulvas poderiam compor um sistema conhecido, reconhecido e respeitado entre os grupos. Elas eram um código de conduta do período (Arrizabalaga, 2005), pois indicavam onde era preciso aparecer

Ciência e Sustentabilidade - CeS / Juazeiro do Norte, v. 4, n. 1, p. 22-38, jan/jun - 2018 
Registros rupestres do Parque Nacional Serra da Capivara-Piauí: breves reflexões sobre a pesquisa antropológica na educação e suas perspectivas interdisciplinares

genitálias (os falos e vulvas) e onde eram desnecessários (JUSTAMAND; FUNARI, 2016, p. 37).

Os autores, nas considerações finais do referido estudo, apontam que há cenas onde antropomorfos aparecem com indumentárias e adornos junto ao corpo e com seus falos a mostra, o pode ser um indicativo de demonstração que determinado gênero humano estaria apto a fazer a atividade retratada na cena, no caso, o sexo masculino. A identificação do gênero dos antropomorfos registrados nas pinturas rupestres do PNSC de acordo com Anne-Marie Pessis (2013) ocorre de três modos.

\begin{abstract}
A definição do gênero aparece nas figuras rupestres particularmente vinculada ao estabelecimento das identidades. Existem três tipos de figuras portadoras de traços de identificação sexual. Aquelas que, sendo simples ou com atributos culturais, apresentam o falo. Outras que possuem traços que permitem identificar o sexo feminino. A presença desse traço diferenciador observa-se apenas nas cenas sexuais, em que existe a intenção de mostrar explicitamente uma ação sexual ou vinculada a temática da reprodução. Não foram identificadas figuras isoladas portadoras desse diferencial sexual. A característica sexual feminina é identificada pela exteriorização da cavidade vaginal. Aparece como um complemento da zona genital que não corresponde às características morfológicas externas do sexo feminino. Não é o sexo feminino que é representado, mas sua função de receptor do falo. [...] Finalmente, existe um terceiro tipo de figura humana que não apresenta qualquer indicador de gênero, pela ausência de todo caráter diferenciador sexual (PESSIS, 2013, p. 128).
\end{abstract}

Além das cenas de práticas sexuais entre antropomorfos masculinos e femininos, há também cenas de práticas entre antropomorfos do mesmo gênero, em grupos e com animais, nos dando um indicativo que no seio dessas sociedades as práticas sexuais estavam inseridas no cotidiano sem nenhum tipo de restrição, conforme visualizado na foto a seguir. 
Foto 04: Prática sexual entre antropomorfos de gêneros diferentes. Local: Toca do Baixão do Perna IV

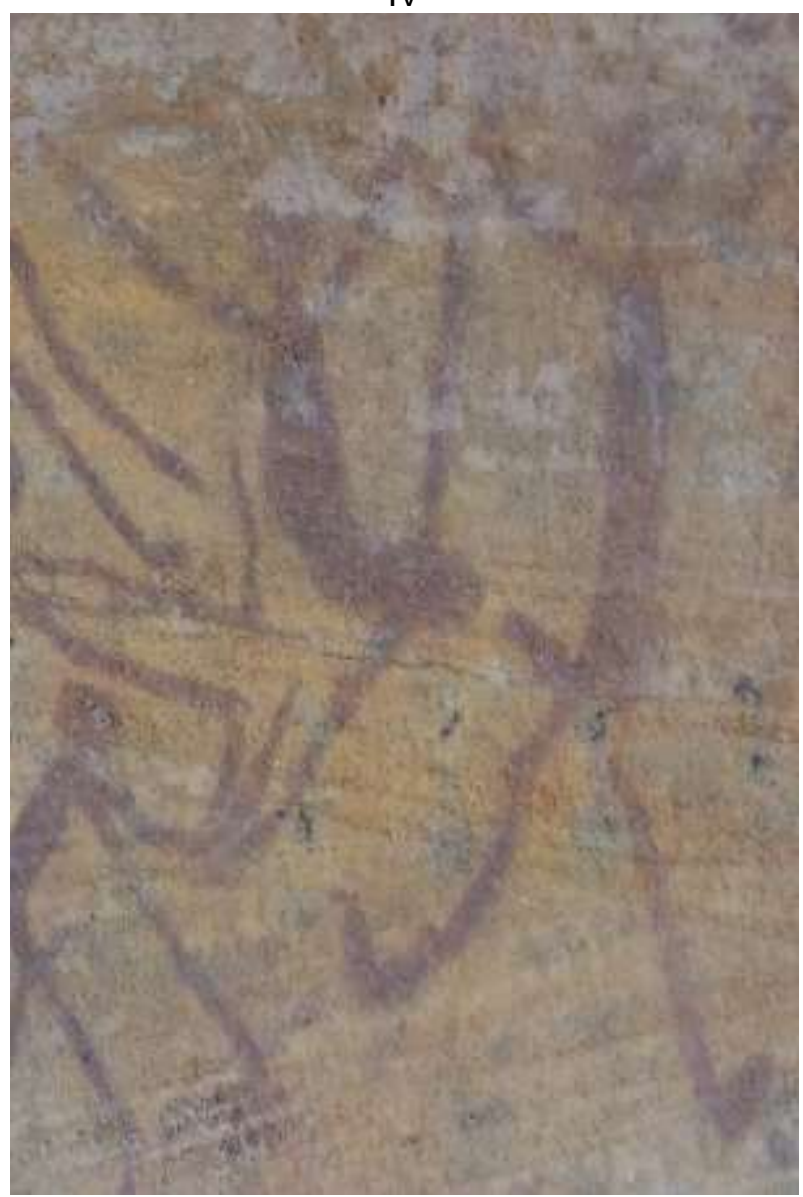

Fonte:. Acervo dos autores (2018).

As múltiplas possibilidades de investigação proporcionadas pelas análises dos registros rupestres, atravessam diversos campos do conhecimento, como pode ser visto, na antropologia, arqueologia, história e outras disciplinas podem produzir saberes e dizeres sobre os povos que habitaram as terras brasilis antes de 1500. É notório, diante das pesquisas bibliográficas apresentadas nesse estudo, que a perspectiva interdisciplinar, e mesmo a transdisciplinar (JUCÁ, 2015), se faz presente para uma ampliação dos estudos sobre o Brasil Antigo.

Como os registos rupestres do PNSC podem promover estudos em antropologia da educação? 
Registros rupestres do Parque Nacional Serra da Capivara-Piauí: breves reflexões sobre a pesquisa antropológica na educação e suas perspectivas interdisciplinares

Na busca de possíveis respostas de caráter reflexivo para a indagação, vale destacar as palavras do cientista social, Amurabi Oliveira (2017, p. 10-11), quando nos aponta que a "antropologia da educação que se desenvolve no Brasil é marcada por uma profunda clivagem institucional, delimitando agendas sensivelmente distintas junto às Faculdades de Educação e aos departamentos de antropologia/ciências sociais". Bernadete Beserra et al. (2017), seguindo a mesma ótica de análise diz que,

[...] a Antropologia perturba porque apresenta o funcionamento cotidiano das instituições modernas. Ele [o conhecimento antropológico] apresenta uma face das instituições que é, em geral, mantida sob segredo, ou simplesmente recalcada. O conhecimento antropológico propõe, de certo modo, um discurso mais concreto, mais calcado no reconhecimento às sociabilidades cotidianas (BESERRA, 2017, p. 16-17).

Diante desse contexto, é necessário ter em a (cons)ciência que fazer uma antropologia da educação relacionada a História Antiga do Brasil com base nos registros rupestres do PNSC, pode envolver o desvelamento de práticas e culturas escolares presentes no cotidiano que, em muitos casos e por interesses micropolíticos atrelados a micropoderes no interior das instituições escolares e universitárias, devem ser mantidas em segredo e recalcadas (JUSTAMAND, 2006b).

Um exemplo que pode ser válido para compreender as relações entre antropologia da educação e os registros rupestres está correlacionado às cenas de práticas sexuais. Como apresentado, os povos que pintaram as rochas contaram sua história, inclusive sua história da sexualidade, que diferentemente dos tempos modernos estava em conexão com a natureza, com o cotidiano das sociedades, sem nenhum tipo de regulamentação em relação a suas práticas sexuais, ou seja, "a sexualidade de nossos ancestrais não era algo a ser reprimido ou escondido, visto que todos os partícipes dos grupos de caçadores e coletores da época tinham acesso às pinturas rupestres feitas por eles mesmos ou por seus ancestrais" (JUSTAMAND; FUNARI, 2014, p. 55), desse modo poderia se indagar, como as culturas escolares atravessadas pela heteronormatividade e homofobia institucional, que muitas vezes advém dos próprios educadores (MEDEIROS, 2017) pensam e discutem esses modos socioculturais das sociedades antigas nos contextos escolares? 
Aponta-se que a proposta de exemplo acima, parte da premissa que o currículo escolar brasileiro discute a origem do homem americano, e uma História Antiga do Brasil que apresenta aos estudantes os achados arqueológicos e antropológicos do PNSC em seus materiais didáticos (JUSTAMAND, 2004b). Porém, como visto durante a pesquisa: Uma aproximação entre arqueologia e educação: relato de uma expedição ao Parque Nacional Serra da Capivara, os livros didáticos pesquisados quando abordavam as temáticas: pré-história e povoamento dos povos nas Américas, apresentavam registros rupestres de sítios arqueológicos estrangeiros (JUSTAMAND, 2004a). Podemos naquele momento perceber que:

\begin{abstract}
O conjunto das imagens e dos textos apresentado nos livros legitima a ideia de uma formação do povo brasileiro que é originário de uma população indígena, de origem bem mais recente, afastando assim o corpo de conhecimentos arqueológicos que ampliam a nossa visão sobre essa formação no tempo mais extenso em que se deu. A apresentação dos sítios arqueológicos europeus e americanos nos livros didáticos legitimam uma hegemonia do conhecimento, através da apresentação de teorias que não realizam conexões com as realidades locais e com outros modos de observar o mesmo fenômeno (GOMES FILHO; MORAIS, 2017c, p. 277).
\end{abstract}

A produção das culturas escolares também perpassa o livro didático, seus (des)usos e abusos. Kazumi Munakata lembra que a ideia de cultura escolar,

[...] refere-se não apenas a normas e regras, explícitas ou não, símbolos e representações, além dos saberes prescritos, mas também, e sobretudo, a práticas, apropriações, atribuições de novos significados, resistências, o que produz configurações múltiplas e variadas, que ocorrem topicamente na escola. Afinal, não há como negar que haja coisas que só existem na escola (MUNAKATA, 2016, p. 122).

O livro didático é o portador dos saberes que circulam no interior das instituições escolares, já que ele existe apenas para a escola, nele está transcrito o que deve ou deveria ser ensinado aos alunos (MUNAKATA, 2016). Por isso, se o livro didático apresenta uma História Antiga do Brasil, que não explana os olhares teóricos e metodológicos oriundos da antropologia e arqueologia brasileira, em especial do PNSC, os estudantes brasileiros entenderam que nossa História enquanto povo dar-se a partir da chagada dos povos europeus nas américas, e que muito antes de 1500, a história resume-se as culturas indígenas, tal como conhecemos na atualidade (JUSTAMAND, 2014). Assim, esses e outros temas

Ciência e Sustentabilidade - CeS / Juazeiro do Norte, v. 4, n. 1, p. 22-38, jan/jun - 2018 
Registros rupestres do Parque Nacional Serra da Capivara-Piauí: breves reflexões sobre a pesquisa antropológica na educação e suas perspectivas interdisciplinares

podem entrelaçar a antropologia da educação e os registros rupestres do Parque Nacional Serra da Capivara, produzindo assim novos conhecimentos sobre as culturas escolares, implicando no (re) conhecimento do atual estado de difusão do conhecimento arqueológico, antropológico e histórico nas escolas e na educação brasileira.

\section{CONSIDERAÇÕES FINAIS}

Os estudos em antropologia da educação buscam compreender os espaços e culturas escolares em suas particularidades. Através da etnografia é possível compreender os arranjos micropolíticos que envolvem os atores escolares e educacionais, estudantes-professores-funcionários e como estes relacionam-se com questões mais amplas socialmente. Tais estudos podem desvelar produções materiais e simbólicas, que muitos desses atores não queriam que venham à tona, sendo este um dos grandes desafios que o "antropólogo da educação-aprendiz" encara em suas idas a campo, uma vez que os resquícios de 500 anos de colonização ainda atravessam as instituições brasileiras (BESERRA et al., 2017; CAVALCANTE, 2017).

Diante desses desafios, percebemos ao longo do estudo que o fazer antropológico na educação brasileira não acontece de modo isolado e disciplinar, mas de modo interdisciplinar, mantendo um diálogo especial com os campos da história, da arqueologia e da educação, pois como lembrando por Neusa Gusmão (1997, s/p) os diálogos entre antropologia e educação abre um "espaço para debate, reflexão e intervenção, que acolhe desde o contexto cultural da aprendizagem, os efeitos sobre a diferença cultural, racial, étnica e de gênero, até os sucessos e insucessos do sistema escolar em face de uma ordem social em mudança".

Diante de tantas possibilidades para a investigação antropológica na educação, em perspectiva interdisciplinar, elegemos como foco de nossas reflexões as pinturas rupestres, em especial as do PNSC, para buscar compreender, mesmo que neste momento em nível teórico, como tais registros pintados nas rochas do município de São Raimundo Nonato no Estado do Piauí, podem influenciar e/ou produzir um modo cultural escolar. Para isso, utilizamos os temas: gênero e 
sexualidade, livro didático e currículo, para apontar as relações entre a antropologia e a educação, desembocando assim nos estudos de antropologia da educação.

Consideramos que os estudos em antropologia da educação, em perspectiva interdisciplinar com a história e a arqueologia, podem proporcionar novos olhares sobre a educação e sobre as instituições escolares e seus funcionamentos materiais e simbólicos, já que o "antropólogo da educação-aprendiz", através da prática etnográfica, poderá compreender o cotidiano destes espaços, conhecendo assim a formação de uma cultura própria do lócus estudado, bem como suas relações com a sociedade (JUSTAMAND, 2015).

\section{AGRADECIMENTOS}

Agradecemos a Fundação Museu do Homem Americano - FUMDHAM.

\section{REFERÊNCIAS}

BESERRA, Bernadete de L. R. et al. Introdução - A escola, a construção do cidadão brasileiro e os riscos e desafios da pesquisa antropológica. In: BESERRA, Bernadete de L. R.; GUSSI, Alcides Fernando.; SALES, Yuri Nóbrega. (Orgs.). Experimentações etnográficas em antropologia da educação. Porto Alegre, RS: Editora Fi, 2017.

BIBLIOTECA NACIONAL DIGITAL. Terra Brasilis. 2015. Disponível em: <https://bndigital.bn.gov.br/artigos/terra-brasilis/>. Acesso em: 12 Fev. 2018. CASTRO, Sádia Gonçalves de. O elogio do cotidiano: a educação ambiental e a pedagogia silenciosa da caatinga no sertão piauiense. Fortaleza: Edições UFC, 2011.

CAVALCANTE, Maria Juraci Maia. À guisa de introdução: a última aula do seminário de educação brasileira. In: GOMES FILHO, Antoniel dos Santos.; MEDEIROS, Jarles Lopes.; CAVALCANTE, Maria Juraci Maia. (Orgs.). Educação Brasileira: ensaios iniciáticos em torno da crise da escola e dos desafios do mundo contemporâneo. Fortaleza: Edições UFC, 2017.

FUMDHAM. Fundação Museu do Homem Americano. 2018. Disponível em: <http://www.fumdham.org.br/o-parque>. Acesso em: 13 Fev. 2018.

GOMES FILHO, Antoniel dos Santos. Experiências educacionais e sociais de travestis no Ceará: um estudo comparado em Juazeiro do Norte e Canindé. Dissertação (Mestrado em Educação) - Universidade Federal do Ceará, Faculdade de Educação, Programa de Pós-Graduação em Educação, Fortaleza, 2017a.

GOMES FILHO, Antoniel dos Santos.; MAGALHÃES, Eloi dos Santos. Performances de travestis nas terras consagradas a São Francisco das Chagas: uma experiência Ciência e Sustentabilidade - CeS / Juazeiro do Norte, v. 4, n. 1, p. 22-38, jan/jun - 2018 
Registros rupestres do Parque Nacional Serra da Capivara-Piauí: breves reflexões sobre a pesquisa antropológica na educação e suas perspectivas interdisciplinares

etnográfica no município de Canindé-Ceará, Brasil. In: Interfaces Científicas Humanas e Sociais, v. 6, n. 2, 2017b. Disponível em:

<http://dx.doi.org/10.17564/2316-3801.2017v6n2p51-64>. Acesso em: 12 Fev. 2018.

GOMES FILHO, Antoniel dos Santos.; MORAIS, Marina Freire Crisóstomo. Uma aproximação entre arqueologia e educação: relato de uma expedição ao Parque Nacional Serra da Capivara. In: GOMES FILHO, Antoniel dos Santos.; MEDEIROS, Jarles Lopes.; CAVALCANTE, Maria Juraci Maia. (Orgs.). Educação Brasileira: ensaios iniciáticos em torno da crise da escola e dos desafios do mundo contemporâneo. Fortaleza: Edições UFC, 2017c.

GUIDON, Niède. Arqueologia da região do Parque Nacional Serra da Capivara Sudeste do Piauí. In: Com ciência - Revista Eletrônica de Jornalismo Científico, 2003. Disponível em: < http://www.comciencia.br/dossies-1-

72/reportagens/arqueologia/arq10.shtml>. Acesso em: 20 Dez. 2017.

GUSMÃO, Neusa Maria Mendes de. Antropologia e educação: Origens de um diálogo. In: Cadernos CEDES, v. 18, n. 43, 1997. Disponível em: $<$ http://www.scielo.br/scielo.php?script=sci_arttext\&pid=S010132621997000200002\& lng=en\&nrm=iso >. Acesso em: 11 Fev. 2018.

ICMBIO. Parque Nacional da Serra da Capivara. Disponível em: < http://www.icmbio.gov.br/portal/o-que-fazemos/visitacao/unidades-abertas-avisitacao/199parque-nacional-da-serra-da-capivara.html>. Acesso em: 22 Jan. 2016.

JUCÁ, Gisafran Nazareno Mota. Prefácio. In: SILVA, Marinalva Freire de.; ARAÚJO, Osmar Hélio de Araújo. (Orgs.). A educação sob a ótica da transdisciplinaridade. João Pessoa: Ideia, 2015.

JUSTAMAND, Michel. A presença das pinturas rupestres nos livros didáticos de História no Brasil: de 1960 a 2000. Revista Espaço Acadêmico. São Paulo, n. 38, 2004b.

. As comunicações e as relações sociais nas pinturas rupestres.

Anuario de Arqueología, Rosário, Argentina. Vol. 7, p. 51-65. 2015.

As pinturas rupestres do Brasil: educação para a vida até hoje. Revista Espaço Acadêmico. São Paulo, n. 41, $2004 a$.

As pinturas rupestres do Brasil: memória e identidade ancestral. Revista Memorare, Tubarão, v. 1, n. 2, p. 118-141, jan./abr. 2014.

As pinturas rupestres na cultura: uma integração fundamental. Embu das Artes: Alexa Cultural, 2006a.

As pinturas rupestres na História e na Antropologia: uma breve contribuição. Francisco Morato: Margê, 2005. 
As pinturas rupestres nos livros didáticos de História. Francisco Morato: Margê, 2006b.

. Comunicar e educar no território brasileiro: uma relação milenar. Embu das Artes: Alexa Cultural, 2012a.

Corpos em evidência: cenas corpóreas antropomorfas rupestres em São Raimundo Nonato (PI). In: Revista Cordis - Revista Eletrônica de História Social da Cidade, n. 7, 2011. Disponível em:

$<$ https://revistas.pucsp.br/index.php/cordis/article/view/10384/7731>. Acesso em: 10 Dez. 2017.

JUSTAMAND, Michel. et al. A arte rupestre em perspectiva histórica: uma história escrita nas rochas. In: Revista de Arqueologia Pública, v.11, n. 1, 2017. Disponível em: <

https://periodicos.sbu.unicamp.br/ojs/index.php/rap/article/view/8648451/16261>. Acesso em: 12 Dez. 2017.

O feminino rupestre em São Raimundo Nonato (Piauí): muito antes de 1500. In: Revista EDUCAmazônia, v. 8, n. 1, 2012b. Disponível em: < https://dialnet.unirioja.es/servlet/articulo?codigo=4133428>. Acesso em: $11 \mathrm{Fev}$. 2016.

JUSTAMAND, Michel.; FUNARI, Pedro Paulo A. Representações da sexualidade e dos falos: nas cenas rupestres de São Raimundo Nonato-Piauí muito antes de 1500. In: Revista Sodebras, v. 9, n. 99, 2014. Disponível em: < http://www.sodebras.com.br/edicoes/N99.pdf>. Acesso em: 13 Dez. 2017.

JUSTAMAND, Michel.; FUNARI, Pedro Paulo A. Representações das genitálias femininas e masculinas nas pinturas rupestres no Parque Nacional Serra da Capivara, PI, Brasil. In: Anuário de Arqueologia, n 8, 2016. Disponível em: < http://rephip.unr.edu.ar/handle/2133/6561 >. Acesso em: 11 Dez. 2017.

LAPLATINE, François. Aprender antropologia. São Paulo: Brasiliense, 2007.

MARTIN, Gabriela. Pré-história do Nordeste do Brasil. 2. ed. Recife: Editora Universitária da UFPE, 1997.

MARTIN, Gabriela.; GUIDON, Niède. A onça e as orantes: uma revisão das classificações tradicionais dos registros rupestres do NE do Brasil. In: Clio Arqueológica, v. 25, n. 2, 2010. Disponível em: <http://www3. ufpe.br/clioarq/images/documentos/V25N1-2010/2010v25n1a1.pdf>. Acesso em: 14 de Fev. 2018.

MEDEIROS, Jarles Lopes de. A escola e os professores diante da problemática da sexualidade: uma perspectiva histórico-sociológica de análise dos discursos e das práticas educacionais. Dissertação (Mestrado em Educação) - Universidade 
Federal do Ceará, Faculdade de Educação, Programa de Pós-Graduação em Educação, Fortaleza, 2017.

MUNAKATA, Kazumi. Livro didático como indício da cultura escolar. In: História da Educação, v. 20, n. 50, 2016. Disponível em: <http://dx.doi.org/10.1590/22363459/624037>. Acesso em: 14 Fev. 2018.

PESSIS, Anne-Marie. Imagens da pré-história. 2. ed. FUMDHAM Ed., 2013.

PESSIS, Anne-Marie; GUIDON, Niède. Registros rupestre e caracterização das etnias pré-históricas. In: VIDAL, Lux. (Org.). Grafismos indígenas: estudos de antropologia estética. 2. ed. São Paulo: Studio Nobel: FAPESP: Editora da Universidade de São Paulo, 2000.

SANTOS, Boaventura de Sousa. Para uma nova visão da Europa: aprender com o Sul. In: Sociologias, v. 18, n. 43, 2016. Disponível em:

<http://dx.doi.org/10.1590/15174522-018004302>. Acesso em: 13 Fev. 2018.

SEEMANN, Jörn. Texto e contexto em mapas do "Descobrimento": uma leitura "entre as linhas" do Terra Brasilis (1519). In: Maquinações (UEL), v. 1. 2007. Disponível em: < http://www.uel.br/prograd/maquinacoes/home.html>. Acesso em: 12 Fev. 2018.

UNESCO. Parque Nacional Serra da Capivara. 2018. Disponível em: < http://www.unesco.org/new/pt/brasilia/culture/world-heritage/list-of-world-heritage-inbrazil/serra-da-capivara/\#c1348680>. Acesso em: 13 Fev. 2018.

VIGARELLO, Georges. O viril e o selvagem das "terras descobertas". In: CORBIN, Alain.; COURTINE, Jean-Jacques.; VIGARELLO, Georges. (Orgs.). História da Virilidade. Petrópolis, RJ: Vozes, 2013. 